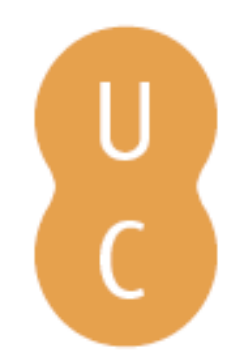

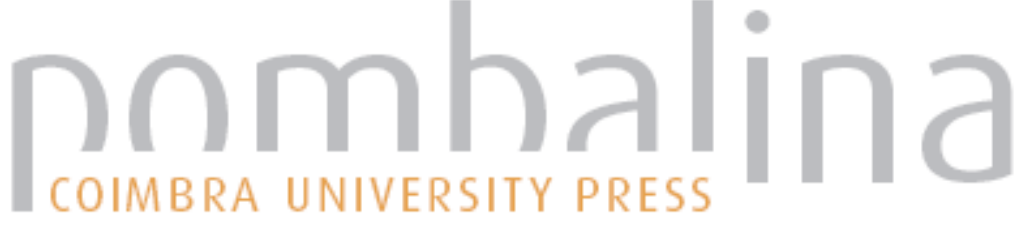

\section{As bibliotecas digitais ou a Noruega no século XXVII}

\author{
Autor(es): $\quad$ Reis, Carlos
}

Publicado por: Imprensa da Universidade de Coimbra

URL

persistente: $\quad$ URI:http://hdl.handle.net/10316.2/36974

DOI: $\quad$ DOI:http://dx.doi.org/10.14195/978-989-26-1045-0_3

Accessed : $\quad$ 26-Apr-2023 10:49:27

A navegação consulta e descarregamento dos títulos inseridos nas Bibliotecas Digitais UC Digitalis, UC Pombalina e UC Impactum, pressupõem a aceitação plena e sem reservas dos Termos e Condições de Uso destas Bibliotecas Digitais, disponíveis em https://digitalis.uc.pt/pt-pt/termos.

Conforme exposto nos referidos Termos e Condições de Uso, o descarregamento de títulos de acesso restrito requer uma licença válida de autorização devendo o utilizador aceder ao(s) documento(s) a partir de um endereço de IP da instituição detentora da supramencionada licença.

Ao utilizador é apenas permitido o descarregamento para uso pessoal, pelo que o emprego do(s) título(s) descarregado(s) para outro fim, designadamente comercial, carece de autorização do respetivo autor ou editor da obra.

Na medida em que todas as obras da UC Digitalis se encontram protegidas pelo Código do Direito de Autor e Direitos Conexos e demais legislação aplicável, toda a cópia, parcial ou total, deste documento, nos casos em que é legalmente admitida, deverá conter ou fazer-se acompanhar por este aviso.

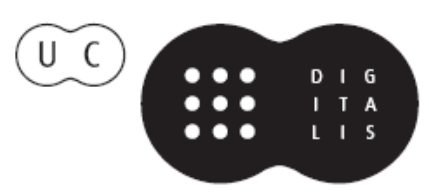



Tendo como pano de fundo as Comemorações dos seus 500 anos, a Biblioteca Geral da Universidade de Coimbra organizou um Congresso Internacional subordinado ao tema "A Biblioteca da Universidade: permanência e metamorfoses", que teve lugar nos dias 16, 17 e 18 de janeiro de 2014, no auditório da Reitoria da Universidade de Coimbra.

O objetivo maior desta reunião científica foi o de refletir sobre o presente e o futuro das bibliotecas que servem públicos universitários. Numa outra vertente, procurou chamar-se a atenção para a importância de que a Biblioteca se reveste, tendo em vista o progresso do conhecimento técnico e científico. Por último, o Congresso pretendeu instituir-se como oportunidade de reflexão prospetiva e como lugar de encontro entre as sensibilidades de todos os que trabalham profissionalmente com livros e com outros suportes de natureza bibliográfica.

Nesse sentido, foram apresentadas Conferências, Mesas Redondas e sessões de Testemunhos em torno de temas como o valor das bibliotecas universitárias, a biblioteca universitária em contexto; as mudanças e os desafios; a biblioteca universitária e a sociedade da informação e conhecimento; o impacto do acesso aberto na comunidade científica, e as bibliotecas digitais. 


\section{CARLOS REIS}

Universidade de Coimbra

University of Coimbra

\section{AS BIBLIOTECAS DIGITAIS OU A NORUEGA NO S ÉCULO XXVII}

DIGITAL LIBRARIES OR $27^{\text {TH }}$ CENTURY NORWAY

RESUMO: A minha intervenção no Congresso Internacional "A Biblioteca da Universidade: Permanência e Metamorfoses" centra-se na articulação entre as chamadas bibliotecas digitais e as bibliotecas que há séculos conhecemos, com particular destaque para as que exercem funções de salvaguarda patrimonial. A análise proposta parte de um esforço de relativização: devemos olhar as bibliotecas digitais tendo em vista as ferramentas, as linguagens e também as oportunidades que o digital faculta e não tanto condicionados por uma visão estática ou passadista do livro e da biblioteca; a bibliomania é, neste caso, má conselheira. Não desligo a reflexão acerca deste tema da minha experiência passada como responsável por uma biblioteca em que se levou a cabo uma experiência pioneira em Portugal, em matéria digital: a Biblioteca Nacional Digital. Equacionam-se, com apoio nessa experiência, alguns dos desafios, das funções, das mudanças e também dos agentes que presentemente intervêm na constituição das chamadas bibliotecas digitais. As injunções do digital e, em geral, da indústria informática são, neste contexto, decisivas; mas não o são menos as interrogações que muitos formulam acerca do destino do livro e, com ele, das bibliotecas.

Ou então e decorrentemente, acerca nas novas funções que elas hão de desempenhar (e porventura desempenham já, por exemplo, como plataformas de distribuição de conteúdos), em particular quando se acentua a trivialização de dispositivos digitais de leitura que incentivam o leitor a consultar a biblioteca a distância.

AbSTRACT: This contribution to the International Conference "A Biblioteca da Universidade: Permanência e Metamorfoses" focuses on the link between the so-called digital libraries and the libraries we have known for centuries, with a particular emphasis on those which are responsible for preserving heritage. The analysis begins with an attempt to put things into perspective: we should consider digital libraries in terms of the tools, languages and opportunities which the digital medium offers, rather than being overly influenced by a static, backward-looking vision of books and libraries; bibliomania is, in this context, a bad counsellor. My reflections on this subject are not unconnected with my experience as the individual responsible for a library involved in a pioneering digital experiment in Portugal, namely the National 
Digital Library. Drawing on this experience, some of the challenges, tasks, changes and agents currently involved in creating digital libraries will be addressed. The demands of the digital age and the IT industry in general are, in this context, crucial: nevertheless, the questions raised by many concerning the future of books and libraries are no less important.

Consequently, they concern the new functions they will have to assume (and may already be serving, as platforms for distributing content, for example), particularly given the fact that digital devices which facilitate long-distance library consultation are becoming commonplace.

1. Pouco tempo antes de começar este texto, chegou-me pela Internet (um medium que bem sintoniza com o tema de que me ocuparei) um contributo a que chamarei de inspiração. Trouxe-o a revista The Atlantic, num breve artigo assinado por Alexis C. Madrigal, em que se anunciava: "A Noruega decidiu digitalizar todos os livros noruegueses» ${ }^{1}$. A matéria não era nova: na edição digital do Público de 15 de dezembro, numa peça não assinada, comentara-se a mesma iniciativa, sublinhando-se que a empresa Google, no seu vasto projeto de digitalização do acervo de muitas bibliotecas por todo o mundo, em Portugal começou precisamente por obras da Biblioteca Geral da Universidade de Coimbra.

De tudo (e não é muito) o que se diz em ambos os artigos destaco aquilo que me interessa neste contexto. Primeiro: de acordo com The Atlantic, a Noruega está muito à frente dos Estados Unidos, no que a esta matéria diz respeito. Segundo: apesar dos esforços da Google e de outros (como é o caso da Digital Public Library of America), "não estamos prontos para o apocalipse", avisa Alexis Madrigal. Atingindo gentes, bens materiais e, naturalmente, livros, a catástrofe global a vir limitará a busca dos arqueólogos digitais do século XXVII a pouca coisa, mas permitirá descobrir uma coleção completa da literatura norueguesa devidamente digitalizada. Terceiro: graças aos seus cuidados digitais de agora, os noruegueses serão, para o século XXVII, o mesmo que os gregos foram

1 Madrigal, Alexis C. - Norway Decided to Digitize All the Norwegian Books. The Atlantic [Em linha]. 3 de dezembro de 2013. [Consult. 21 Set. 2014]. Disponível na WWW em: < http://www.theatlantic.com/technology/archive/2013/12/norwaydecided-to-digitize-all-the-norwegian-books/282008/> 
para o Renascimento e as crianças das colónias espaciais desse futuro chamar-se-ão Per, Henrik, Amalie e Sigrid. Por fim: "As nossas bibliotecas fazem o que podem, mas a ideia de digitalizar literalmente todos os livros publicados neste país é uma meta pela qual deveríamos trabalhar e que deveríamos financiar.» ${ }^{2}$

Há uma ideia que brilha no fundo destas conjeturas, enunciadas no tom provocatório que bem se percebe: a ideia (que é também um valor) da Memória, devidamente maiusculada aqui, para que sejam sublinhadas as suas dimensões identitária, cultural, civilizacional e antropológica. Justamente: a Memória que nos habituámos, desde há muitos séculos, a guardar nos livros das bibliotecas, por forma a que neles se cumpram os princípios de estabilidade e de permanência que a expressão scripta manent bem representa.

Não estou absolutamente certo, contudo, de que para os humanos remanescentes do século XXVII a dita Memória tenha o significado e a relevância que hoje ainda lhe reconhecemos. Quer isto dizer que os labores de digitalização dos noruegueses não serão devidamente reconhecidos nesse futuro longínquo? Ou que a nossa reflexão conjunta e a dos demais que nos precederam, acerca do digital e da digitalização, do livro e do seu futuro, das bibliotecas digitais e da sua função, dos leitores e da sua relação com as bibliotecas, nada disso faz sentido? Não digo tanto, mas atrevo-me a afirmar o seguinte: essa reflexão só será pertinente na medida em que nela soubermos inscrever uma marca de relatividade e mesmo de algum distanciamento crítico, quanto à valia, à função e à responsabilidade social dos instrumentos que nos servem e de que nos servimos, incluindo as bibliotecas, sejam digitais, sejam analógicas. Dito noutros termos: tendemos a olhar e a pensar o livro e a biblioteca com os olhos e com os juízos que são os nossos, herdados de muitos séculos de uso e de aprimoramento técnico. Fazemo-lo, contudo, como se ambos, livro e biblioteca, fossem eternos, o que está longe de ser verdade; poucas vezes somos capazes de perceber que, se ponderamos o presente

\footnotetext{
2 MADrigal, Alexis C. - Norway decided do digitize all the norwegain books.
} 
e perspetivamos o futuro do livro e da biblioteca, em formato digital e em ambiente eletrónico, então devemos relativizar conceitos (e mesmo preconceitos), valores e rotinas que vêm do passado, mas que talvez não tenham futuro. Porque o presente está a mudar, com a celeridade própria de um tempo que, além do mais, "outra mudança faz de mor espanto,/ Que não se muda já como soía”.

Ao que fica dito acrescento mais alguns testemunhos, provindos ainda das fontes que citei. Na peça do jornal Público, o jornalista anónimo faz duas observações significativas. Uma: no cenário traçado - o das bibliotecas digitalizadas -, é possível «consultar todos os livros das bibliotecas nacionais de diferentes países através do computador». Outra (e concluindo): "Resta dizer que a completa digitalização da Biblioteca Nacional da Noruega não representará a morte da coleção física, que se manterá intacta» ${ }^{3}$. Dois comentários, abrindo caminho ao que vem depois. Primeiro: o jornalista afirma (e bem) que se trata de "consultar" e não de ler, pela razão não-dita de que o acúmulo de informação assim disponibilizada torna impossível outra coisa que não seja essa mera "Consulta", com a ligeireza (com a superficialidade?) que ela pressupõe; e a isto junta a menção ao computador enquanto veículo ou terminal de acesso aos textos, como se ele fosse (e não é) o único instrumento que hoje manejamos para aquele efeito, o que fixa estas palavras num passado já anacrónico. Noutros termos: logo que escreveu o seu texto, o jornalista deixou-o desatualizado, no respeitante aos instrumentos de que nos servimos hoje para leitura de mensagens em regime digital. Segundo comentário: na afirmação de que a "coleção física" será salvaguardada, o autor insinua uma certa insegurança (de que não tem o exclusivo, como bem se sabe) em relação à capacidade de o digital cumprir cabalmente a função de preservação da memória que, por muito tempo, coube sobretudo ao livro. Como quem diz: à cautela, guarde-se o livro. Ou então aquelas

3 A Noruega vai digitalizar todos os seus livros e disponibilizá-los gratuitamente. Público [Em linha]. 15 de dezembro de 2013. [Consult. 21 Set. 2014]. Disponível na WWW em: <http://www.publico.pt/culturaipsilon/noticia/a-noruega-vai-digitalizartodos-os-seus-livros-e-disponibilizalos-gratuitamente-1616404> 
palavras expressam um certo fetichismo do impresso de que muitos tardam em libertar-se - se é que alguma vez se libertarão.

2. Postas as coisas nestes termos, esclareço a razão de ser desta minha intervenção e os parâmetros que a balizam. Fixo o seu alfa e o seu ómega em dois estádios da minha vivência pessoal, no tocante ao universo das bibliotecas, com os seus fascínios, os seus desafios, os seus mistérios e, às vezes, as suas perversidades.

Entre 1998 e 2002 (o período do alfa) fui diretor da Biblioteca Nacional (hoje Biblioteca Nacional de Portugal). Tive, então, o privilégio de conhecer por dentro uma instituição em que muito aprendi, para o tempo de então e para o que veio depois. Esse tempo que veio depois (o do ómega) é o do investigador que sou de novo, com expectativas, com solicitações, com exigências e, às vezes, com irritações em relação às bibliotecas de que continuo a necessitar como elemento de apoio fundamental para o meu trabalho; bibliotecas que, esclareço desde já, me surgem agora em vacilante e perigosa oscilação entre o passado e o futuro.

Pelo meio, ficaram, no mundo das bibliotecas e não só nele, profundas mutações técnicas, culturais, económicas, sociológicas e psicológicas, que drasticamente alteraram (e continuam a alterar) a relação do leitor com a informação de que carece, seja qual for o suporte ou o formato em que ela nos surge. Para se ter uma ideia: a simples expressão «seja qual for o suporte ou o formato» era coisa relativamente pacífica em 1998; presentemente, cada novo suporte ou formato traz consigo a premência de novas aprendizagens e competências para a utilização das máquinas e das linguagens de que nos servimos para aceder à informação. O que faz do leitor uma entidade bem diferente daqueloutro (o leitor analógico, para simplificar) a quem, até aos anos 90, bastava saber ler palavras e frases inscritas em livros e em revistas de papel e, complementarmente, dispor de uma mínima literacia bibliotecária. O novo leitor - o leitor do tempo digital - é uma figura obrigatoriamente tocada pela síndrome da multiplicidade.

Falo da síndrome da multiplicidade com o intuito de trazer a esta intervenção o contributo de um autor e de um livro que muito me mar- 
caram nos últimos anos e que inevitavelmente aqui comparecem. Falo de Italo Calvino e das suas Seis Propostas para o Próximo Milénió ${ }^{4}$ (1985), e lembro que as propriedades que nele se anteveem como dominantes neste nosso tempo (e entre elas a multiplicidade) têm sido amplamente confirmadas, até mesmo no mundo das bibliotecas (voltarei a este assunto). Calvino foi, para mais, autor de um admirável romance, Se numa Noite de Inverno um Viajante, que é uma brilhante combinação de alegoria, paródia e movimento narrativo, colocando no seu centro o livro convencional, o leitor e a leitura, as seduções e as armadilhas da ficção.

3. Quase inevitavelmente, mencionarei o projeto e o desenvolvimento da chamada Biblioteca Nacional Digital (BND) que, na viragem do século passado para este, quis ser (e foi) uma inovação que outras instituições similares conheciam já, mas sempre pelo meio de dúvidas e incertezas de vária ordem. Para além delas, uma certeza era já possível, nesse tempo: a de que o digital entrara no trabalho bibliotecário e nas rotinas do leitor como auxiliar com um potencial operatório inquestionável; de tal forma o fez que acabaram por ser postos em causa vários componentes da entidade biblioteca, por muito tempo encarada como espaço pouco menos do que imutável, fechado e estabilizado em funções que pareciam perenes.

Recordo a experiência da Biblioteca Nacional Digital, servindo-me de documentos de orientação que então foram produzidos ${ }^{5}$, com dois propósitos: em primeiro lugar, para que se observe a relação entre a semente que se lançou e o que dela nasceu, depois se foi desenvolvendo e está à vista e uso de todos na página da Biblioteca Nacional de Portugal6; em segundo lugar, para que se possa apreciar o espaço que medeia entre o que então se previa e o que no presente se faz, porque mudaram as

\footnotetext{
4 CAlvino, Italo - Seis propostas para o novo milénio. Lisboa: Teorema, 1990.

5 Para a preparação desses documentos e sobretudo para o desenvolvimento da Biblioteca Nacional Digital muito contribuiu o trabalho da subdiretora de então, Fernanda Guedes de Campos, a cuja visão, dinamismo e competência aquela iniciativa muito ficou a dever.

6 Biblioteca Nacional De Portugal - Biblioteca nacional digital. Lisboa: BNP, 2002. [Consult. 21 Set. 2014]. Disponível na WWW em: <URL:http://purl.pt/index/geral/PT/index.html>
} 
circunstâncias, os recursos disponíveis e as soluções técnicas. Tudo isto e as expectativas do leitor, que hoje deseja ter "tudo na Internet".

Assim, a Biblioteca Nacional Digital assentava em dois princípios ético-culturais: o princípio da responsabilidade patrimonial (que é genericamente a razão de ser de qualquer biblioteca ou arquivo nacional) e o princípio da democratização do acesso, mesmo sabendo-se que ela não é atingida só pelo passe de mágica da digitalização e da integração em rede, porque os utilizadores são cidadãos comuns, condicionados por níveis variados de info-inclusão. Deste modo, a Biblioteca Nacional Digital propunha-se estruturar instrumentos e operações facultadas pelas tecnologias da informação e da comunicação, promovendo e disponibilizando edições digitais e documentos digitalizados, no quadro das funções legais próprias de uma biblioteca nacional. Para além disso, a Biblioteca Nacional Digital incidia sobre documentos de diversa natureza: livros, manuscritos, mapas, gravuras, etc. E desde logo ficava claro que esta seria uma iniciativa em progresso, dependendo da evolução de tecnologias e de metodologias sempre em mudança. Ou seja: um projeto em construção, sujeito, como tal, a ampliações e a reajustamentos funcionais.

De forma obviamente sintética, enuncio quatro elementos estruturantes da Biblioteca Nacional Digital:

i. A BND contemplava, em primeira instância, conteúdos procurados pela comunidade dos leitores de uma biblioteca nacional, privilegiando-se sobretudo as chamadas fontes documentais.

ii. A BND deveria formar um acervo coerente e orientado, com a designação Construção da Memória, traduzindo a identidade da Biblioteca Nacional e das suas coleções mais significativas.

iii. A BND procurava cumprir funções de extensão cultural, designadamente realizando exposições virtuais, como contributo para a difusão e valorização dos fundos documentais da Biblioteca Nacional.

iv. Uma valência específica da BND: a sua articulação com a chamada Biblioteca Nacional a distância, entendida como funcionalidade e não como entidade com densidade própria. 
Parece oportuno reconhecer o seguinte: estes elementos mantêm-se praticamente intocáveis na atualidade do que hoje continua a ser a Biblioteca Nacional Digital, o que resulta também do facto, infelizmente raro entre nós, de quem veio depois ter sabido desenvolver e aprofundar o que outros lançaram.

4. Este será o momento adequado para se olhar de novo, com algum distanciamento (o meu distanciamento, entenda-se), uma iniciativa que prometia muito, cumpriu e cumpre uma parte importante das suas promessas e foi deixando por conta de outras entidades a responsabilidade de acudir a expectativas hoje muito mais complexas e diversificadas do que há quinze anos. Por outro lado, houve já tempo para que se refletisse sobre questões de natureza técnica, cultural, jurídica e social que as chamadas bibliotecas digitais desencadeiam e de encontrar as soluções possíveis para essas questões, mesmo sabendo-se que elas rapidamente se esgotam, num cenário por natureza instável.

Dessa reflexão destaco três domínios específicos: o da dimensão e alcance da biblioteca digital, o do seu potencial de disseminação da informação bibliográfica e documental (com alguns riscos inevitáveis pelo meio) e o das alternativas que ela hoje encontra e com que obrigatoriamente se articula.

Primeiro: nas condições atuais, a biblioteca digital que replique, na sua plenitude, a biblioteca de papel, é um horizonte praticamente inatingível, a não ser para os diligentes noruegueses de que falei; e mesmo estes terão que trabalhar até 2020, antes de darem a empresa por completa. A este respeito, recordo a pergunta insistente que era feita, nos começos da Biblioteca Nacional Digital, por jornalistas que se interessaram pelo assunto: todos os livros da Biblioteca Nacional estão já digitalizados? Não direi, como uma personagem de Eça, que isto era «falar com a leviandade de um jornalista"; prefiro tolerar o absurdo da pergunta, levando em conta a despreparada inocência de quem a fazia. Ressalve-se que, na dita pergunta, uma coisa estava implicitamente adquirida: a biblioteca digital era (e de certa forma continua a ser) uma biblioteca digitalizada, não um repositório informacional de objetos nascidos digitais. Deste tipo de 
repositórios - ou da biblioteca plenamente digital e não apenas digitalizada - haverá que falar noutro momento e com outra demora.

Segundo: o potencial de disseminação conseguido pela biblioteca digital carece de articulação com um outro conceito, sem o qual ela desempenhará estimáveis funções da ordem da preservação, mas pouco mais do que isso. Esse outro conceito é o de biblioteca em rede, contando com as ferramentas, com as dinâmicas e com o ilimitado alcance da Worl Wide Web, da Internet e dos avanços da engenharia informática: navegadores intrépidos, potentes motores de busca, nutridos servidores, protocolos engenhosos, softwares argutos, códigos em mutação (da Web 1.0 à Web 3.0 e assim por diante), nuvens que recolhem informação "lá no assento etéreo" onde ela sobe, como memória não do amor do poeta mas dos livros que um dia puros vimos. Tudo isto e o mais que não domino (voltarei a isto), sendo certo que aquilo que disse e o que ficou por dizer fazem parte de um admirável mas já não novo mundo, muito bem caracterizado por um eminente sociólogo da cultura da Internet, Manuel Castells. Disse Castells que "O novo sistema de comunicação transforma radicalmente o espaço e o tempo, as dimensões fundamentais da vida humana». E acrescentou:

"As localidades são despojadas do seu sentido cultural, histórico e geográfico e reintegram-se em redes funcionais ou em conjuntos de imagens, ocasionando um espaço de fluxos que substitui o espaço de lugares. O tempo é apagado no novo sistema de comunicação já que passado, presente e futuro podem ser programados para interagir, entre si, na mesma mensagem. O espaço de fluxos e o tempo atemporal são as bases fundadoras de uma nova cultura, que transcende e inclui a diversidade dos sistemas de representação historicamente transmitidos: a cultura da virtualidade real, onde o faz-de-conta se vai tornando realidade. ${ }^{7}$

As bibliotecas digitais colaboram na construção do espaço de fluxos e do tempo atemporal, na medida em que permitem anular distâncias e tornar presente, de forma fulminante, o nosso passado canónico e remoto,

7 Castells, Manuel - A sociedade em rede. Lisboa: Fund. Calouste Gulbenkian, 2005, p. 492. 
quase inacessível e sacralizado pela aura que se desprende do documento reservado, às vezes único e com forte carga simbólica. E assim, consultar (não digo ler), em versão digitalizada e à distância, a primeira edição d'Os Lusíadas é cómodo, é barato e é seguro para todos, até mesmo para o leitor, que não corre o risco de ser contaminado por uma arcaica bactéria vinda lá do século XVI e escondida entre duas rimas de uma qualquer estância do genial poema épico; em vez dela, só mesmo algum vírus informático poderá afetar a saúde do terminal de leitura. Sem a presença real da obra palpável perde-se o tal efeito de aura. Mas não se pode ter tudo, sendo certo que, além do mais, ninguém disse que as bibliotecas digitais eram perfeitas.

Não passo adiante sem aflorar (não mais do que isso) uma questão melindrosa, atinente a um campo de trabalho que me interessa. Falo agora da forma e dos termos em que as bibliotecas digitais lidam com coleções de reservados, em particular naquele subdomínio que é o dos documentos de arquivo literário. Os espólios, para nos entendermos. O que é claro para mim: do ponto de vista da preservação e do acesso reservado, o digital traz consigo vantagens inquestionáveis; tenho disso experiência pessoal, que só não explano para não me alongar. O que não é pacífico para mim: que documentos de espólio literário ou congéneres - manuscritos em diversos estádios de elaboração e outros materiais similares - devam ser lançados na rede (como já aconteceu), sem quaisquer critérios de acesso. Fazê-lo, é esquecer a natureza privada, às vezes íntima, de tais documentos; é cancelar, sem mais nem porquê, o princípio da reserva (que, antes do digital e da rede, vigorava por razões que não eram só da ordem da salvaguarda material); e é ignorar que, na rede, o acesso facilmente se confunde com a devassa e a consulta com intuito científico confina com o voyeurismo; do mesmo modo, a publicidade à escala global do que nasceu como pessoal e intransmissível comporta riscos e consequências que consabidamente preocupam os analistas da sociabilidade virtual e em rede dos nossos dias. Dar acesso irrestrito a uma carta privada de Eça ou a um borrão incipiente de Pessoa não é o mesmo que facultar sem reservas a versão digitalizada da tal primeira edição d'Os Lusíadas - texto que o seu autor quis que fosse público. Isto é para mim tão claro que os reparos que a esta posição 
possam ser formulados (às vezes esgrimindo absurdamente a recusa de qualquer censura, coisa que só por miopia pode ser argumentada) são facilmente desarmados pela seguinte pergunta (pergunta retórica, é claro): algum dos meus leitores gostaria que, dentro de 20, 30 ou mais anos, os seus papéis privados ou mesmo os seus ficheiros informáticos pessoais fossem parar à Internet? Isto para além de se saber que a publicidade desregrada dos espólios, a par da sua fetichização, podem gerar (e geram mesmo, conheço alguns casos) efeitos perversos: o escritor pode passar a escrever e a emendar, seja em que suporte for, para depois ser estudado pela crítica genética, ao alcance de um clique.

Um terceiro e último domínio de cogitação sintetiza-se com estas palavras: não estamos sós. Ou seja: aquilo que, nos primórdios das bibliotecas digitais, teve uma feição fortemente patrimonial, por conta de instituições oficiais ou similares (as bibliotecas nacionais, mas não só elas), com configuração e com estrutura não raro semelhantes e com financiamento maioritariamente público, conta agora com outros e poderosos agentes. E com interesses, com motivações e com públicos diversificados, sendo cada vez mais evidente que a heterogeneidade desses interesses, motivações e públicos dificulta a padronização de procedimentos e a convergência de propósitos. Penso aqui em iniciativas de tão variada dimensão, fatura e alcance como o Google Books ou o Projeto Gutenberg, a Europeana ou a Digital Public Library of America ${ }^{8}$, a HathiTrust Digital Library ou The European Library, a Biblioteca Virtual Miguel de Cervantes, as ainda operativas bibliotecas nacionais digitais ou os variados repositórios construídos em contexto universitário. Ao mesmo tempo, tenho consciência de que as lógicas que eram próprias das bibliotecas digitais dos tempos pioneiros se alteraram, em especial as de índole patrimonial, que foram integrando consórcios, muitas vezes vocacionados para funcionarem como plataformas de acesso a conteúdos de proveniências muito distintas.

8 Darnton, Robert - The National Digital Public Library Is Launched! The New York Review of Books [Em linha]. 25 de abril de 2013. [Consult. 21 Set. 2014]. Disponível na WWW em: <URL: http://www.nybooks.com/articles/archives/2013/apr/25/ national-digital-public-library-launched/>. 
Apenas dois comentários quanto à diversidade que fica mencionada. Um: o facto de ser hoje muito amplo o leque de opções e muito abundantes os agentes em atuação não significa que o Estado possa ou deva alhear-se das responsabilidades que neste campo continua a ter. Mudaram os formatos, mas não as exigências da preservação e da divulgação patrimonial; e aos que dizem que "está tudo na Internet" é preciso explicar algumas coisas, porque a ligeireza dos juízos tem limites. Com efeito, o "tudo» que supostamente está na Internet nem sempre cumpre exigências de qualidade técnica, de validade científica, de segurança e de durabilidade que nos garantam que esse «tudo» estará ao nosso dispor por muito tempo. O segundo comentário começa por duas perguntas, formuladas a partir do conhecimento de iniciativas como a Biblioteca Virtual Miguel de Cervantes, com a projeção que assume no mundo de língua espanhola: como fica, neste aspeto, a chamada Lusofonia, essa de que muito se fala mas que pouco se vê? Existe ou existirá uma biblioteca digital conjunta que, a partir da experiência acumulada em Portugal e no Brasil, conduza a um amplo repositório documental em língua portuguesa, em formato digital e em rede? Só para lembrar algumas coisas básicas: o mapa-múndi das bibliotecas digitais traduz uma geografia do desenvolvimento social, do poder político e da representação linguística; o Google Books não é uma entidade gerada por desinteressada filantropia; e a hegemonia do inglês como língua de conhecimento não é uma inevitabilidade, mas sim uma opção política e económica, com efeitos culturais e cognitivos, indo muito além da escolha inocente de um idioma fácil em que «todos nos entendemos». Idioma fácil e, para alguns, abençoado, se fizermos fé nas palavras atribuídas a uma antiga governadora do Texas, Miriam "Ma" Ferguson, quando rebateu o ensino de outras línguas que não o inglês: "Se o inglês era bom para Jesus Cristo", teria dito ela, "também é bom para as crianças do Texas.»?

9 CARTER, Jimmy - Talking Peace [Em linha]. [S.1.: s.n.], 2001. [Consult. 21 Set. 2014]. Disponível na WWW em: <URL:http://web.archive.org/web/20090806185021/www. international.ucla.edu/burkle/article. asp?parentid=2198>. 
5. Insisto no que afirmei inicialmente: a presente reflexão situa-me no tempo-ómega que é o da minha condição de leitor e investigador, isto é, alguém que se acha dependente, às vezes carente, não raro perplexo e mesmo um pouco angustiado perante o espetáculo do mundo dos livros e dos seus sucedâneos, das bibliotecas e dos novos mistérios que elas encerram.

No seu romance O Ano da Morte de Ricardo Reis, José Saramago inseriu, em epígrafe, um verso de uma ode de Ricardo Reis: «Sábio é o que se contenta com o espetáculo do mundo». Não contesto uma máxima que em si traz a marca da filosofia quase contemplativa do heterónimo pessoano; mas, não me conformando com ela, acrescento, por minha conta: sábio é o que, perante o espetáculo do mundo dos livros e das bibliotecas de agora, não se contenta com tudo, pergunta, discute, acautela-se e às vezes desconfia. E mais: sábio é o que, na sua condição de leitor-dependente afetado por dúvidas, está atento à injunção de poderes - por exemplo: o da indústria informática, com os seus interesses próprios - que condicionam e determinam o formato das bibliotecas e dos livros, na era digital.

De sobra sei que isso a que chamo, à falta de melhor, era do digital, foi anunciado desde há algumas décadas, por quem teve aquela dose de lúcida intuição que a antecipação do futuro (hoje presente) sempre requer. Em 1997, Espen J. Aarseth, um dos precursores das chamadas humanidades digitais (um norueguês, para que conste), escreveu, num livro que é já um clássico:

"É crença comum que a rápida evolução no campo da tecnologia digital desde meados do século $\mathrm{XX}$ até ao presente originou (entre outros resultados igualmente espantosos) formas radicalmente novas de escrita e de leitura. Esta perspetiva, estimulada pela crescente experiência pessoal de tecnologia informática entre a massa académica, pode observar-se até em estudos literários que, desde 1984, crescentemente têm procurado captar e construir textos mediados por computador como objetos de crítica literária.» 10

10 AARSETH, Espen J. - Cibertexto. Perspectivas sobre a literatura ergódica. Lisboa: Pedro de Rosete, 2005, p. 31. 
Ao escrever estas palavras, Aarseth situava-se num subdomínio específico, o da escrita literária, que neste momento não vem ao caso, a não ser na medida em que ela se processava e processa (processar é, neste contexto, um termo absolutamente decisivo) num formato e num ambiente que tudo têm que ver com o universo das bibliotecas digitais. Mas já antes de Aarseth e com a agudeza premonitória que só os grandes pensadores alcançam, Calvino esboçava, em 1985, nas Lezione americane, seis propostas para o presente milénio, que não chegou a completar nem a ver publicadas. Mas elas estão connosco e com uma assombrosa atualidade, para o que respeita ao mundo das bibliotecas digitais. Recordo: leveza, velocidade, exatidão, visibilidade, multiplicidade e consistência.

Três propriedades calvinianas podemos observar na biblioteca digital, propriedades que recordo aqui, a partir do que noutro local escrevi ${ }^{11}$ :

i. Leveza. A biblioteca digital é leve e desmaterializada, ocupa espaço reduzido, é eminentemente dinâmica e pode estar em todos os lugares ao mesmo tempo, "deslocando-se" com a agilidade do que é (rigorosamente) imponderável. A leveza de que fala o ensaísta deve-se à informática e ao digital: «É verdade», diz Calvino, "que o software não poderia exercer os poderes da sua leveza senão por meio do peso do hardware; mas é o software que comanda, que atua sobre o mundo exterior e as máquinas, que só existem em função do software, evoluindo de modo a elaborar programas mais complexos». E acrescenta: nesta segunda revolução industrial "continuam a existir máquinas de ferro, mas obedecem aos bits sem peso» 12 .

ii. Velocidade. A biblioteca digital é veloz na transmissão de dados, na rapidez de acesso, no descarregamento de documentos e na transferência de suportes. Calvino adverte, contudo: "O tema que nos interessa aqui não é a velocidade física, mas sim a relação

11 Reis, Carlos - Informação e conhecimento. Propostas, presenças e ausências. Leituras. Revista da Biblioteca Nacional. Lisboa: BN. Série 3, n. 8 (Abril-Outubro, 2001), p. 29-30.

12 Calvino, Italo - Seis Propostas para o Novo Milénio. Lisboa: Teorema, 1990, p. 22. 
entre a velocidade física e a velocidade mental» ${ }^{13}$. É no sentido da velocidade mental que se orienta a biblioteca digital, porque é a rapidez do conhecimento, com a sua inelutável vocação para a caducidade e com o seu poder de renovação, que a motiva e determina a sua existência. E também uma nova epistemologia do acesso à informação e aos documentos, com efeitos inevitáveis na ordem cultural, jurídica, educativa e política.

iii. Multiplicidade. "O conhecimento como multiplicidade», escreve Calvino, «é um fio condutor que liga as obras maiores, tanto do que se designa por modernismo como daquilo a que se chama pós-moderno, um fio que (...) eu desejaria ver desenrolar-se no próximo milénio»14. Obras maiores são naturalmente as que a biblioteca guarda, como testemunho da memória cultural e artística; obra maior é a própria biblioteca digital, reconstruída sob o signo dessa multiplicidade - de funções, de linguagens, de instrumentos, de especialidades e de comportamentos -, que exige a quem nela trabalha e a quem a frequenta a aceitação de um tal princípio.

Estas (e mesmo as demais) propriedades antecipadas por Calvino determinam certamente, em diversos aspetos da constituição e do aprofundamento da biblioteca digital, métodos de gestão bibliotecária, procedimentos de acesso e opções de preservação distintos dos que regiam a biblioteca convencional. Desta, que durou e vigorou por muitos séculos, até à biblioteca digital, transitou-se com uma celeridade (outra vez a velocidade) impressionante e isso terá tido custos importantes: em poucos anos, passou-se da biblioteca a que chamo convencional para a biblioteca eletrónica, desta para a biblioteca virtual e por fim (por fim? Tenho dúvidas...) para a biblioteca digital ${ }^{15}$. O que não quer dizer que cada uma destas etapas rasure o que a anterior instalou.

\footnotetext{
13 Calvino, Italo - Seis Propostas para o Novo Milénio, p. 57.

14 Calvino, Italo - Seis Propostas para o Novo Milénio, p. 137.

15 Cf. Baili, Carla - La biblioteca in rede. Milano: Editrice Bibliografica, 1998.
} 
Não vou adentrar-me em tão complexas noções e cogitações. Reduzo-me a uma referência com o timbre da IFLA, a poderosa federação que congraça associações de bibliotecas de todo o mundo. Em 2011, por ocasião da $36^{a}$ sessão da assembleia geral da UNESCO, a IFLA apresentou e fez ratificar um manifesto em prol das bibliotecas digitais. Apoiava-se aquele manifesto em duas orientações programáticas: por um lado, no propósito de colaborar na concretização dos chamados Objetivos de Desenvolvimento do Milénio, pela via da anulação da exclusão digital; por outro lado, no aprofundamento de orientações decorrentes da Cimeira Mundial para a Sociedade da Informação (segunda fase, 2005), no respeitante à criação de programas nacionais de digitalização. Pois bem: em 2011 a IFLA caracterizava assim a biblioteca digital: "Uma biblioteca digital é uma coleção em linha de objetos digitais, de qualidade garantida, que são criados ou coleccionados e geridos em concordância com princípios internacionais reconhecidos para o desenvolvimento de coleções e tornados acessíveis de modo coerente e sustentável, suportados por serviços necessários para permitirem que utilizadores encontrem e explorem os recursos» 16

6. Levaria muito longe a análise minuciosa de tudo (e muito é) o que está implicado nesta caracterização. Limito-me a algumas questões que têm que ver com o que se seguirá. Esta, antes de mais: tal como no passado (mas ele era menos veloz, mais simples e os seus objetos mais densos), as bibliotecas digitais de agora não podem deixar de ter em conta o que é (e o que será) o objeto digital que elas criam ou recebem e que organizam em coleções. Movemo-nos, assim, num espaço de ambiguidades e de provisórias definições, em geral impostas pela natureza fluida e instável dos tais objetos digitais: a condição do livro (ou do seu homólogo) no século XXI remete para a forma do chamado e-book, designação hoje consabidamente atravessada por ambiguidades e por imprecisões, mesmo

16 IfLA/UnEsco - Manifesto for Digital Libraries [Em linha]. [S.1.]: IFLA, 2010. [Consult. 21 Set. 2014]. Disponível na WWW em: <URL:http://www.ifla.org/publications/ iflaunesco-manifesto-for-digital-libraries>. 
porque a sua construção conceptual e funcional deve muito, afinal, à tradição conceptual e funcional do livro de papel ${ }^{17}$.

O debate em torno do dito (mesmo que mal dito) e-book, com relevância para o universo das bibliotecas, arrasta outras questões, que não apenas as ambiguidades mencionadas. Envolve as novas dinâmicas (compositivas, editoriais, de distribuição, de aquisição e de acesso) geradas pelo documento eletrónico; as atitudes cognitivas e psicoculturais que ele gera; os complementos de informação multimédia que se lhe associam; as exigências de armazenamento e de atualização de software que ele requer; as singularidades de tratamento biblioteconómico que exige; os reajustamentos que o acesso ao objeto digital impõe, etc. Todo um leque de conceitos e de valorações já não emergentes mas praticamente dominantes ${ }^{18}$; foram eles que tornaram obsoletos outros conceitos e valorações, que pareciam inamovíveis e que por muito tempo condicionaram o trabalho de investigadores e de leitores, presentemente "reformatados" também eles, em função daquilo a que chamo uma nova epistemologia do documento, do seu tratamento e do seu uso, em contexto bibliotecário.

Era aqui que eu queria chegar. Olho para a biblioteca digital e situo-me nela em termos muito diversos do que acontecia nas bibliotecas em que há poucos anos investiguei e estudei; há poucos anos e ainda neste tempo, para que conste. Essa nova atitude envolve até uma diferente relação do meu corpo com a informação a que acedo (texto, imagem, som, gráfico, base de dados), com mais razão sempre que estão em causa objetos nascidos digitais, eventualmente comandados pela lógica e pela dinâmica das representações hipertextuais e hipermédia. Nesse ambiente - que já não é o de uma sala fechada, num espaço e num tempo delimitados -, tendo a navegar, mais do que a ler. Não resisto à tentação e peço tolerância para o exagero: na biblioteca digital, navegar é preciso, ler não é preciso (voltarei a esta imagem, que tem autor). Mais: na biblioteca

17 Chartier, Roger - Languages, Books, and Reading from the Printed World to the Digital Text. Critical Inquiry. Chicago: The University of Chicago Press. Vol. 31, N. ${ }^{\circ} 1$ Autumn (2004), p. 133-152.

18 Furtado, José Afonso - O Papel e o Pixel. Do impresso ao Digital. Continuidades e Transformações. Lisboa: Ariadne, 2007. 
digital, a representação e a atuação dos agentes em cena é triangular e não dual, como antes acontecia.

Explico-me, com a ajuda do ethos do cinema e das intrigas que nele circulam. Na biblioteca do passado, desenvolvia-se uma lenta, surda e arriscada atração fatal entre o leitor e a bibliotecária (mais raramente entre a leitora e o bibliotecário). Movidos por uma espécie de instinto fatal, ambos ambicionavam possuir um obscuro objeto de desejo chamado livro: perseguido pelo primeiro, guardado pela segunda, ele materializava-se, por breve tempo e depois de enviesadas diligências, numa mesa de leitura, resgatado do silêncio em que jazia, entre milhares ou milhões de congéneres. Um happy end difícil, mas bem saboroso.

A biblioteca digital fez entrar em cena um terceiro elemento e transformou em triângulo amoroso aquela já arcaica atração dual: junta-se agora aos dois de que falei o informático, uma espécie de alien vindo não da Galáxia Gutenberg, mas da Galáxia Microsoft. É esta nova personagem que na biblioteca digital fortemente determina o comportamento e o destino das outras duas, a quem impõe instrumentos, atitudes e processos de conhecimento inimaginados no tempo em que o livro tinha corpo; e não falo no corpo do livro por força de expressão, como veremos. Para evitar um desenlace trágico, as personagens do triângulo (ménage à trois seria excessivo) assumem sem complexos a multiplicidade dos três vértices e são estimuladas (rapidamente, é claro) a fundirem-se em uma única figura, mesmo que por breve tempo. E assim, num tempo pós-moderno de fronteiras rasuradas, de papéis moventes e de acentuados relativismos axiológicos, o leitor e a bibliotecária da biblioteca digital aprendem informática, ao mesmo tempo que o alien, rendido aos fascínios da biblioteca, convive com algumas das suas palavras mágicas: acesso, preservação, classificação, etc. The end? "Not so fast", como se diz nos melhores westerns. Falta responder a uma pergunta insidiosa, em que ecoa um título de José Saramago: que farei com estes livros? E, consumada a transferência para outro suporte, em diferente formato, que fará a biblioteca convencional com a massa documental de revistas, jornais e miscelâneas, uma massa documental que ocupa quilómetros de estantes, em salas, caves, torres e depósitos? Antes de responder, trato 
brevemente e já para ir terminando, do corpo do livro, num tempo em que ele vai deixando de o ter ${ }^{19}$.

7. Do corpo do livro ou, se a expressão não chocar, da escatologia do livro. A pergunta de um milhão de dólares, muitas vezes repetida, é esta: o livro vai morrer, conforme alguns anunciam? Se a resposta for afirmativa, a pergunta seguinte será, inevitavelmente: e as bibliotecas, desaparecerão igualmente? Pelos vistos sim, ao menos no formato em que foram concebidas e têm existido, sempre que o livro foi encarado como ultima ratio para a memória dos homens.

Um dos problemas desta reflexão é o seguinte: a questionação em torno da eventual morte dos livros e da obsolescência das bibliotecas «de papel» é usualmente desenvolvida por devotos do livro; trata-se quase sempre de personalidades muito influentes no campo cultural e político, que viveram, foram formados e até ganharam e ganham a vida em função do livro como obscuro objeto de desejo. Do livro e da biblioteca entendida como lugar físico, recheado de volumes com peso, textura e cheiro, apetecidos até por legiões de bibliófagos. Exemplo paradigmático de bibliofilia quase feita bibliomania: Umberto Eco. Em vários textos, mas sobretudo em dois a que vou referir-me, o autor d'O Nome da Rosa - não por acaso um romance acerca da biblioteca como espaço físico e do livro como objeto de disputa sujeito a destruição - assume-se como o Dan Gallagher ${ }^{20}$ dos livros e das bibliotecas, ou seja, como o advogado nova-iorquino atraído por uma mulher fatal a cujas seduções é incapaz de resistir.

19 Albert Manguel descreveu de forma muito sugestiva os termos em que o leitor se relaciona com a dimensão e com o aspeto físico dos livros: "My hands, choosing a book to take to bed or to the readind-desk, for the train or for a gift, consider the form as much as the content. Depending on the occasion, depending on the place where I've chosen to read, I prefer something small and cosy or ample and substantial. Books declare themselves through their titles, their authors, their places in a catalogue or on a bookshelf, the illustrations on their jackets; books also declare themselves through their size. At different times and in different places I have come to expect certain books to look a certain way, and, as in all fashions, these changing features fix a precise quality onto a book's definition. I judge a book by its cover; I judge a book by its shape." (Manguel, 1996, p. 125).

20 Protagonista de Atração Fatal (1987), de Adrien Lyne, interpretado pelo ator Michael Douglas. 
No ensaio De Bibliotheca (1986), Eco coloca-se sintomaticamente sob o signo d'A Biblioteca de Babel de Jorge Luis Borges, para evocar um espaço com arquitetura própria, labiríntico, misterioso e quase hostil, por onde circula um leitor sedento de descobertas bibliográficas. Com a ironia que se lhe reconhece, Umberto Eco enuncia os dezanove pontos de um modelo negativo de biblioteca, que é aquela em que os catálogos são confusos, os tempos de espera longos, a reprodução é um calvário, o bibliotecário desconfia do leitor, os apertados horários limitam a consulta, o empréstimo torna-se impossível e não se sabe onde param os livros desaparecidos. Tudo perversidades (estas e outras mais que não digo) que conduzem, por oposição, a um modelo de biblioteca à medida do homem: "alegre, com a possibilidade de se tomar um café, com a possibilidade de dois estudantes numa tarde se sentarem num maple e, não digo de se entregarem a um amplexo indecente, mas de consumarem parte do seu flirt na biblioteca, enquanto retiram ou voltam a pôr nas estantes alguns livros de interesse científico, isto é, uma biblioteca onde nos apeteça ir, e que se vá transformando gradualmente numa grande máquina de tempos livres” ${ }^{21}$.

Não sei onde fica esta biblioteca e talvez Umberto Eco também não. Mas sei que aquela outra e muito imperfeita biblioteca de que ele fala (conheço algumas parecidas com ela...) está a pedir a alternativa que se ia esboçando, no momento em que o grande ensaísta escreveu este texto: a biblioteca digital. Quase vinte anos depois, quando Umberto Eco voltou ao tema, a propósito da refundada Biblioteca de Alexandria, parecem esquecidas as provações de que o texto de 1986 nos fala; proclama-se então a necessidade da biblioteca como repositório da "memória vegetal» (expressão do autor) e declara-se: elas «devem sobreviver como museus que guardam as descobertas do passado» ${ }^{22}$. Por fim, Eco não podia ignorar a realidade do digital nesse ano de 2003, porque a informática entrara já irreversivelmente na produção dos textos e, por consequência,

\footnotetext{
21 Eco, Umberto - A Biblioteca. Lisboa: Difel, 1991, p. 45.

22 Eco, Umberto - Muito além da Internet. [Em linha]. Dezembro, 2003. [Consult. 20 Set. 2014]. Disponível na WWW em: <URL: http://www.ofaj.com.br/textos_conteudo.php?cod=16>.
} 
no trabalho e na organização da biblioteca. E contudo, a voz de uma espécie de ressentimento anti-digital insiste na explanação de funcionalidades que, mesmo que deslocadas para o computador, são herdeiras da lógica textual do livro de papel: "Não há dúvida», escreve Eco, "de que o computador se tornou, acima de tudo, um instrumento alfabético. Em sua tela, correm palavras e linhas escritas e, para usar um computador, é preciso saber ler e escrever.» 23 .

É este um argumentário bem típico de quem pertence a uma geração que navega entre duas águas, as do livro (e da biblioteca) de papel e as do documento (e da biblioteca) digital, ressalvando sempre, é claro, a placidez das primeiras contra os perigosos baixios das segundas, imagem que colho de um título de Nicholas Carr, evidentemente ${ }^{24}$. Mas no momento da verdade - esse em que afloram gostos, valorações e rotinas herdados de uma tradição multissecular -, sobrevém e afirma-se uma conceção do ser digital (na expressão consagrada de Negroponte) como sujeito transgressor e como fenómeno residual: «Disseram-me», nota Eco, "que certos hackers, que cresceram diante de computadores e não têm o costume de folhear livros, leram afinal grandes obras-primas da literatura na forma de livros eletrônicos, mas creio que tal fenômeno permanece muito restrito.» 25

Não posso (embora gostasse) adentrar-me pela fenomenologia da leitura na era do digital. Sobre essa matéria existe abundante bibliografia, subscrita pelas legiões dos Horácios e dos Curiácios que comandam os dois bandos em confronto, o do digital e o do analógico. Lembro apenas duas coisas, com segura repercussão na metamorfose que a biblioteca conhece, ao mudar gradualmente para o digital. Uma: em 2003, quando Eco falou na Biblioteca de Alexandria, estavam ainda a aparecer os primeiros dispositivos de recolha, de armazenamento e de leitura de tex-

23 Outro passo significativo: "Após passar 12 horas diante de uma mesa de computador, meus olhos parecem duas bolas de tênis e sinto a necessidade de me recostar confortavelmente numa poltrona e ler um jornal ou talvez um bom poema." (Eco, 2003).

${ }^{24}$ CARR, Nicholas - The Shallous how the Internet is Changing the Way we Read, Think and Remember. London: Atlantic Books, 2010.

25 Eco, Umberto - Muito além da Internet. 
tos com a configuração do trivial tablet de agora. Com ele, o corpo do texto humanizou-se, mimetizando, em vários aspetos, a forma do livro e acrescentando-lhe novas funcionalidades de leitura; com ele, o terminal da biblioteca digital deslocaliza-se e ganha a leveza de que falava Calvino: o leitor acede à biblioteca virtualmente em qualquer lugar do mundo (em tempo: Umberto Eco lembrar-se-á da dimensão, da portabilidade e do formato daquelas simpáticas e pouco higiénicas ardósias em que, nos anos 50, aprendíamos a escrever e a fazer contas? De certa forma, faltava só aperfeiçoá-las).

Segunda observação: estamos aqui perante um jogo de poderes. A resistência do Umberto Eco de 2003 desaparecerá (talvez até já tenha desaparecido), à medida que as novas gerações de estudantes e de estudiosos dispuserem da biblioteca digital como recurso em que a leveza, a velocidade e a multiplicidade se impõem, com vantagem sobre o peso, a densidade, a feição unilinear e a vagarosa circulação do livro de papel na biblioteca convencional. Da tensão que ainda hoje vivemos, na passagem de um paradigma lecto-escritural para outro (e de uma biblioteca para outra), falou N. Katherine Hayles num ensaio recente; "os estudantes» notou Hayles, «leem incessantemente no meio digital e escrevem também nesse meio, mas apenas raramente são encorajados a fazê-lo em aulas de literatura ou em ambiente que encorajem a transferência de competências de leitura impressa para o digital e vice-versa. As duas vias, impressa e digital, correm lado a lado, mas mensagens de cada uma delas não saltam para o outro lado» 26 .

8. Parafraseando um título de Manuel António Pina: ainda não é o fim nem o princípio da biblioteca, calma é apenas um pouco tarde. Um pouco tarde, se olharmos em volta e virmos que a biblioteca do tempo digital tem muita coisa a fazer, mais até do que supõe Roger Chartier quando observa: "Uma das tarefas essenciais das bibliotecas é reunir, proteger, catalogar e tornar acessíveis os objetos físicos que transmitiram as obras

${ }^{26}$ HaYles, Katherine - "Como Lemos Nós: Close, Hiper, Máquina". Revista de Estudos Literários. Coimbra: Centro de Literatura Portuguesa. Volume 2 (2012), p. 60. 
escritas do passado» 27 . Cabe perguntar: e quanto aos objetos nascidos digitais? Quem trata de os reunir, proteger, catalogar e tornar acessíveis? Está a biblioteca preparada, em termos de recursos humanos, técnicos e financeiros para ser, plenamente, biblioteca digital? No lugar onde me encontro, como leitor-dependente que hoje sou (naquela aceção que antes contemplei), não tenho condições para responder, mas sei que não é possível ignorar estas questões.

Retomo a paráfrase: ainda não é o fim nem o princípio do livro, talvez estejamos até longe do biblioclasmo de que fala Fernando Rodríguez de la Flor, num livro intensamente apocalíptico e provocatório ${ }^{28}$. Num tempo como o nosso, em que é exuberante a produção e a edição de livros, paradoxalmente aproxima-se, segundo o autor, o fim da hegemonia de uma cultura baseada no excesso do impresso; foi esse excesso que, sobretudo no mundo das universidades e perante as massas invasivas de livros, conduziu "à construção, no interior do campus universitário, daquele que é o edifício emblemático neste âmbito, as bibliotecas, últimos redutos onde vai morrer um fluxo livresco, cuja corrente não para de crescer»29. De novo aqui, fala-se de biblioteca no seu sentido convencional, de entidade fisicamente densa e "pesada»; quando, em 1997, lançou as suas provocações, o autor não podia ainda conhecer o poder refundacional da biblioteca digital e a nova epistemologia do documento (documento eletrónico, bem entendido) que ela traz consigo.

Por outro lado, se biblioclasmo existe, ele começou dentro da biblioteca. O seu cavalo de Tróia foi, como lembra Roger Chartier, não tanto a entrada da digitalização na biblioteca (deste pecado ela está inocente), mas, antes disso, a microfilmagem massiva de livros e de periódicos; o que levou à destruição ou à venda de colecções originais, para se conseguir espaço dedicado a novas aquisições. A hecatombe foi suspensa, mas

27 ChARTIER, Roger - Languages, books, and reading from the printed world to the digital text, p. 150.

28 Rodríguez de La Flor, Fernando - Biblioclasmo. Por uma prática crítica da lectoescrita. Lisboa: Edições Cotovia, 2004.

29 Rodríguez de La Flor, Fernando - Biblioclasmo. Por uma prática crítica da lectoescrita, p. 37. 
isso não impediu que se falasse de "assalto ao papel» e de "massacre do livro»30_31, no contexto de um debate que (suponho) não estará encerrado. Trata-se nesse debate da síndrome do excesso a que já aludi, tendo que ver com o peso e com o volume que a publicação impressa pressupõe, acentuada por séculos de produção bibliográfica que a salvaguarda da memória obriga a preservar.

Desde há muito que a preocupação com aquele excesso está representada no testemunho de muitos dos que com ele convivem, de certa forma contrariando uma condição lectoral e uma forma de entender a biblioteca que, goste-se ou não, hoje estão postas em causa. Ou, quando muito, restringidas à bibliomania de uma minoria às vezes sem consciência desse seu estatuto minoritário. Há imagens que dessa minoria retivemos, em testemunhos fortemente impressivos, por aquilo que revelam de uma vivência da biblioteca que hoje parece irrecuperável. Em dois desses leitores do passado a leitura e a biblioteca acham-se sintomaticamente ligadas à imagem da torre. Lembro o admirável e bem conhecido soneto de Quevedo, escrito no confinamento da Torre de Juan Abad, em Ciudad Real; é na solidão da torre e da biblioteca que o poeta desterrado em 1620 encontra a confidente companhia do livro, que o guia até às vozes do passado já morto, mas tornado presente pelo poder da leitura. E diz:

\begin{abstract}
Retirado en la paz de estos desiertos, con pocos pero doctos libros juntos, vivo en conversación con los difuntos y escucho con mis ojos a los muertos. ${ }^{32}$
\end{abstract}

30 BARKER, Nicholas - Double Fold: Libraries and the Assault on Paper. New York Review of Books [Em linha]. 15 de abril de 2001. [Consult. 21 Set. 2014]. Disponível na WwW em: <URL:https://www.nytimes.com/books/first/b/baker-fold.html>.

31 O texto de Darnton deu lugar a uma discussão, DARnton, Robert - The Great Book Massacre' An Exchange. New York Review of Books [Em linha]. 14 de março de 2002. [Consult. 21 Set. 2014]. Disponível na WWW em: <URL: http://www.nybooks.com/articles/ archives/2002/mar/14/the-great-book-massacre-an-exchange/>.

32 Quevedo, Francisco de - Antología Poética. Madrid: Biblioteca Nueva, 1999, p. 169. 
Já antes de Quevedo, no fim do século XVI, foi também numa torre-biblioteca que Michel de Montaigne se recolheu a uma solidão que favorecia a leitura e a meditação de que resultaram os Essais de 1580, desenvolvidos em mais um volume em 1588 e sempre objeto de reescrita, até que a morte sobreveio, em 1592. A partir desse lugar físico e simbólico, lugar de poder e de ascendente sobre os outros, o senhor de Montaigne governa os seus domínios e a sua casa: "Chez moy, je me destourne un peu plus souvent à ma librairie, d'où tout d'une main, je commande à mon mesnage»; é nesse reduto a vários títulos sobranceiro que Montaigne colhe um saber longamente ensaiado, no sentido mais rico do termo, saber que impõe, todavia, uma existência de drástico isolamento que deixa à porta da biblioteca outros deveres: "C'est là mon siege. J'essaie à m'en rendre la domination pure: et à soustraire ce seul coin à la communauté et conjugale, et filiale, et civile.»33

E contudo, na mesma época em que Quevedo e Montaigne encontram na biblioteca o refúgio que nenhum outro lugar concede, já se questiona a bondade dos livros e da sua acumulação, bem como, claro está, os efeitos perversos da leitura. Um dos episódios mais marcantes do longo trajeto do relacionamento dos homens com os livros é o do ataque à biblioteca do Cavaleiro da Mancha. Estamos agora no capítulo VI do Quijote, onde se trata "del donoso y grande escrutinio que el cura y el barbero hicieron en la librería de nuestro ingenioso hidalgo". Era aquela uma biblioteca pequena para os critérios de hoje, mas certamente avultada para a época e para aquele lugar da Mancha, "de cuyo nombre no quiero acordarme». Digo avultada a pensar na aceção que remete para a dimensão física; o que se diz no texto é o seguinte: "Entraron dentro todos, y la ama con ellos, y hallaron más de cien cuerpos de libros grandes muy bien encuadernados, y otros pequeños»34.

33 Montaigne, Michel de - Les Essais. The Montaigne Project [Em linha], p. 828. [Consult. 20 Set. 2014]. Disponível na WwW em: <http://www.lib.uchicago.edu/efts/ARTFL/projects/ montaigne/>.

34 Cervantes, Miguel de - Don Quijote de la Mancha. Madrid: Empresa Pública Don Quijote, 2005, p. 68. 
Os livros têm, então, corpo, conforme muito mais tarde confirmou o Leitor feito personagem, em Se numa Noite de Inverto um Viajante, a tal alegoria composta por Italo Calvino ${ }^{35}$. O escrutínio operado sobre a biblioteca de Dom Quixote, seguido da queima da maioria daqueles corpos, é um exercício crítico (trata-se de saber que livros devem escapar à destruição), do mesmo modo que é um trabalho material, num lugar físico, que depois acaba por ser emparedado. Como se o lamentável destino da biblioteca do Cavaleiro da Triste Figura fosse epítome e prenúncio do que muitas vezes aconteceu ao longo da História, que bem mostra, em muitos e trágicos episódios, os riscos que correm os livros por terem corpo e por estarem depositados num lugar concreto, ao alcance da intolerância e da violenta ignorância dos homens.

9. Muito tempo depois do Quijote, quando a prática da leitura, a organização dos livros e o estatuto do leitor tinham mudado radicalmente, é já o excesso dos livros enquanto, de novo, objetos materiais que atormenta quem frequenta a biblioteca. Esse tempo é o do livro industrializado e progressivamente democratizado, gerando um fenómeno que Eça de Queirós descreveu em 1886, num texto notável de intuição sociológica, quando aludiu ao desaparecimento do leitor e à emergência do público. O termo leitura, diz Eça, "há cem anos, sugeria logo a imagem duma livraria silenciosa, com bustos de Platão e de Séneca, uma ampla poltrona almofadada, uma janela aberta sobre os aromas dum jardim: e neste retiro austero de paz estudiosa, um homem fino, erudito, saboreando linha a linha o seu livro, num recolhimento quase amoroso»36. Quando a democratização do livro faz desaparecer aquele ser individual, que era

35 Refiro-me ao conhecido episódio em que o leitor enfrenta, na livraria, várias categorias de livros, como se avançasse por um campo hostil e povoado por inimigos abundantes: "Vê que te foi possível reduzir o número ilimitado de forças em campo a um conjunto que embora muito grande se pode estimar num número finito, mesmo que este relativo alívio seja atraiçoado pelas emboscadas dos Livros Lidos Há Tanto Tempo Que Seria Hora De Os Releres e dos Livros Que Fazes Sempre De Conta Que Leste E Que Seria Hora De Te Decidires A Lê-los De Facto" (Calvino, 1995, p. 10).

36 QueIrós, Eça de - Cartas Públicas. Edição de Ana Teresa Peixinho. Lisboa: Imprensa Nacional-Casa da Moeda, 2009, p. 188. 
"O leitor amigo", aparece, em vez dele, "a turba que se chama o Público, que lê alto e à pressa no rumor das ruas.»37

O Jacinto d'A Cidade $e$ as Serras não se mistura certamente com aquela turba. Mas nem por isso ele deixa de ser atormentado por aquilo a que, no romance de Eça, se chama "a invasão dos livros no 202". Livros que ocupam espaço, que tapam a luz do dia e que extravasam os limites da biblioteca, alastrando malevolamente por todo o palacete. Não posso agora, como é evidente, demorar-me no comentário que bem mereceria essa risonha paródia das ilusões de uma cultura livresca, ostentada na dimensão, na arrumação (ou na desarrumação), no aspeto material e até na agressividade dos objetos-livros. É o amigo Zé Fernandes (amigo de Jacinto, entenda-se) quem sofre essa traiçoeira agressividade do livro:

«Mais amargamente porém me lembro da noite histórica em que, no meu quarto, moído e mole de um passeio a Versalhes, com as pálpebras poeirentas e meio adormecidas, tive de desalojar do meu leito, praguejando, um pavoroso Dicionário de Indústria em trinta e sete volumes! Senti então a suprema fartura do livro. Ajeitando, com murros, os travesseiros, maldisse a Imprensa, a facúndia humana... E já me estirara, adormecia, quando topei, quase parti a preciosa rótula do joelho, contra a lombada de um tomo que velhacamente se aninhara entre a parede e os colchões» 38 .

Certamente que o Jacinto apologista da ciência e da inovação técnica teria aceitado substituir a sua vistosa biblioteca de trinta mil volumes pela leveza de um discreto servidor informático e por um terminal de leitura, disponibilizando as versões digitalizadas dos seus livros. Nenhum ficheiro eletrónico se atreveria a entrar na cama de Zé Fernandes e o 202 ganharia mais uma máquina para fazer companhia às muitas que já o povoavam, em tempo de fascínio finissecular por novidades técnicas e instrumentais que assombravam o mundo. Estou certo de que a ama, o cura e o barbeiro que destruíram a biblioteca de Dom Quixote não

\footnotetext{
37 Queirós, Eça de - Cartas Públicas, p. 189.

38 QueIrós, Eça de - A cidade e as serras. Lisboa: Livros do Brasil, [s.d.], p. 73.
} 
chegariam a tanto, se a digitalização daqueles "corpos de livros» tivesse sido completada pelas maravilhas da computação em nuvem: os ditos livros teriam ficado fora do alcance daquele zelo destruidor. O que não significaria, é claro (mas essa é já outra história), proteção absoluta e segurança plena.

A biblioteca digital não é, bem sei, a garantia de um mundo bibliotecário perfeito, nem cancela radicalmente a biblioteca impressa. Ela é tão-só a resposta a necessidades e a solicitações várias, bem antigas algumas delas, uma resposta que primeiro se estranhou, mas que já se entranhou. Foi e está a ser dada essa resposta com avanços e com recuos, com vantagens e com resistências, vindas estas sobretudo de quantos medem a mudança inevitável das coisas e das pessoas pelos critérios da sua formação e dos seus valores. Se foi assim com o livro, com a máquina a vapor, com o automóvel e com a televisão, não tinha como não ser assim com a biblioteca digital.

Dela dependemos cada vez mais. Com ela poderemos ler mais e também melhor, à medida que o nosso corpo e a nossa mente se forem conformando a objetos que pedem outros gestos e outros modos de conhecer. $\mathrm{Na}$ biblioteca digital navegamos velozmente guiados pela bússola de um ethos do saber, da investigação e da cultura que se fundam em valores diferentes dos que foram e são os meus, mas que certamente não são nem serão os de quantos, no tal século XXVII dos Per, Henrik, Amalie e Sigrid descendentes dos noruegueses, olharem a biblioteca digital como uma arqueológica e bizarra experiência de um tempo perdido.

Aqueles que não moldarem o seu corpo e a sua mente à biblioteca digital ficarão irremediavelmente para trás. Melhor fora que entendessem o exemplo de quem soube adaptar-se a novos usos do livro, ainda na era do impresso, sem pudores nem complexos. Volto, para o ilustrar, àquele episódio da agressão perpetrada, n'A Cidade e as Serras, por um volumoso Dicionário de Indústria. Tendo, por fim, adormecido, Zé Fernandes deambula, em sonho, por uma Paris invadida por livros e neles metamorfoseada: tudo são livros, tudo tem o formato do livro. Por fim, o amigo de Jacinto sobe ao Paraíso e nele avista «o Ancião da Eternidade, aquele que não tem Manhã nem Tarde». Cito: 
(...) Entre fundas estantes de ouro abarrotadas de códices, sentado em vetustíssimos fólios (...) - o Altíssimo lia. A fronte superdivina que concebera o Mundo pousava sobre a mão superforte que o Mundo criara - e o Criador lia e sorria. Ousei, arrepiado de sagrado horror, espreitar por cima do seu ombro coruscante. O livro era brochado, de três francos... O Eterno lia Voltaire, numa edição barata, e sorria. 39

De Jesus Cristo disse-nos depois Fernando Pessoa «que não sabia nada de finanças/Nem consta que tivesse biblioteca». Não assim com o Deus Padre, como Zé Fernandes pôde ver. E nós com ele. Por mim, estou convicto de que, assim como se ajeitou às edições brochadas, em breve o Altíssimo poderá ler num tablet os livros da Biblioteca Geral da Universidade de Coimbra, quando ela for uma biblioteca digital.

\section{Referências bibliográficas}

AARseth, Espen J. - Cibertexto. Perspectivas sobre a literatura ergódica. Lisboa: Pedra de Roseta, 2005.

BARKer, Nicholas - Double Fold: Libraries and the Assault on Paper. New York Review of Books [Em linha]. 15 de abril de 2001. [Consult. 21 Set. 2014]. Disponível na WWW em: <URL:https://www.nytimes.com/books/first/b/baker-fold.html>.

BASILI, Carla - La biblioteca in rete. Milano: Editrice Bibliografica, 1998.

Biblioteca Nacional de Portugal - Biblioteca nacional digital. Lisboa: BNP, 2002. [Consult. 21 Set. 2014]. Disponível na WWW em: <URL:http://purl.pt/ index/geral/PT/index.html>.

CAlvino, Italo - Se Numa Noite de Inverno Um Viajante. Lisboa: Círculo de Leitores, 1995.

Calvino, Italo - Seis Propostas para o Próximo Milénio. Lisboa: Teorema, 1990.

CARR, Nicholas - The Shallows. How the Internet is Changing the Way we Read, Think and Remember. London: Atlantic Books, 2010.

\footnotetext{
39 QueIrós, Eça de - A cidade e as serras, p. 74.
} 
CARTER, Jimmy - Talking Peace [Em linha]. [S.1.: s.n.], 2001. [Consult. 21 Set. 2014]. Disponível na WWW em: <URL:http://web.archive.org/web/20090806185021/ www.international.ucla.edu/burkle/article.asp?parentid=2198>

CASTElls, Manuel - A Sociedade em Rede. Lisboa: Fund. Calouste Gulbenkian, 2005.

Cervantes, Miguel de - Don Quijote de la Mancha. Madrid: Empresa Pública Don Quijote, 2005.

CHARTIER, Roger - Languages, Books, and Reading from the Printed Word to the Digital Text. Critical Inquiry. Chicago: The University of Chicago Press. Vol. 31, n. ${ }^{\circ} 1$ Autumn (2004). p. 133-152.

DARnton, Robert - The Great Book Massacre. New York Review of Books. [Em linha]. 26 de abril de 2001. [Consult. 21 Set. 2014]. Disponível na WWW em: <URL: http://wWw.nybooks.com/articles/archives/2001/apr/26/ the-great-book-massacre/>

DARnton, Robert - The Great Book Massacre' An Exchange. New York Review of Books [Em linha]. 14 de março de 2002. [Consult. 21 Set. 2014]. Disponível na WWW em: <URL: http://WWw.nybooks.com/articles/archives/2002/mar/14/ the-great-book-massacre-an-exchange/>

DARnton, Robert - The National Digital Public Library Is Launched! The New York Review of Books [Em linha]. 25 de abril de 2013. [Consult. 21 Set. 2014]. Disponível na WWW em: <URL: http://Www.nybooks.com/articles/archives/2013/ apr/25/national-digital-public-library-launched/>

Eco, Umberto - A Biblioteca. Lisboa: Difel, 1991.

ECo, Umberto - Muito além da Internet. Infohome@ofaj.com.br [Em linha]. Dezembro, 2003. [Consult. 20 Set. 2014]. Disponível na WWW em: <URL: http://www. ofaj.com.br/textos_conteudo.php?cod=16>

Furtado, José Afonso - O Papel e o Pixel. Do impresso ao digital. Continuidades e transformações. Lisboa: Ariadne, 2007.

HaYles, Katherine - Como Lemos Nós: Close, Hiper, Máquina. Revista de Estudos Literários. Coimbra: Centro de Literatura Portuguesa. Volume 2 (2012), p. 57-96. IFLA/UNESCO - Manifesto for Digital Libraries [Em linha]. [S.1.]: IFLA, 2010. [Consult. 21 Set. 2014]. Disponível na WWW em: <URL:http://www.ifla.org/publications/ iflaunesco-manifesto-for-digital-libraries $>$

Madrigal, Alexis C. - Norway Decided to Digitize All the Norwegian Books. The Atlantic [Em linha]. 3 de dezembro de 2013. [Consult. 21 Set. 2014]. Disponí- 
vel na WWW em: < http://www.theatlantic.com/technology/archive/2013/12/ norway-decided-to-digitize-all-the-norwegian-books/282008/>

Manguel Alberto - A History of Reading. New York: Viking Penguin, 1996.

Montaigne, Michel de - Les Essais. The Montaigne Project [Em linha]. [Consult. 20 Set. 2014]. Disponível na WWW em: < http://www.lib.uchicago.edu/efts/ ARTFL/projects/montaigne/>

A Noruega vai digitalizar todos os seus livros e disponibilizá-los gratuitamente. Público [Em linha]. 15 de dezembro de 2013. [Consult. 21 Set. 2014]. Disponível na WWW em: <http://www.publico.pt/culturaipsilon/noticia/a-noruega-vai-digitalizar-todos-os-seus-livros-e-disponibilizalos-gratuitamente-1616404> Queirós, Eça de - Cartas Públicas. Edição de Ana Teresa Peixinho. Lisboa: Imprensa Nacional-Casa da Moeda, 2009.

QueIrós, Eça de - A Cidade e as Serras. Lisboa: Livros do Brasil, s.d.

Quevedo, Francisco de - Antología Poética. Madrid: Biblioteca Nueva, 1999.

REIs, Carlos - Informação e conhecimento. Propostas, presenças e ausências. Leituras. Revista da Biblioteca Nacional. Lisboa. S. 3, n. ${ }^{\circ}$ 8, Abril-Outubro (2001), p. 19-30.

Rodríguez de La Flor, Fernando - Biblioclasmo. Por uma prática crítica da lecto-escrita. Lisboa: Edições Cotovia, 2004. 
José Augusto Cardoso Bernardes é Professor da Faculdade de Letras da Universidade de Coimbra e Diretor da Biblioteca Geral da Universidade

Ana Maria Eva Miguéis é coordenadora do Serviço Integrado das Bibliotecas da Universidade de Coimbra

Carla Ferreira é bibliotecária nos Serviços de Biblioteca e Documentação da Faculdade de Letras da Universidade de Coimbra. 


\section{Série Documentos}

Imprensa da Universidade de Coimbra

Coimbra University Press

2015

C •

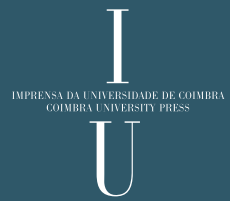

